\title{
Assessment of Renal Functions in Infants with Acute Gastroenteritis and Dehydration
}

\author{
Dr. S. Sandeep
}

Assistant professor, Department of Pediatrics, Maheshwara Medical College, Isnapur (V) Sangareddy dist, Telangana State, India.

Address for communication: Assistant Professor, Department of Pediatrics, Maheshwara Medical College, Isnapur (V) Sangareddy dist- 503207. Telangana State, India. Email: sandeep80552003@gmail.com

DOI : 10.47799/pimr.0802.20

\section{Abstract}

Background: Acute gastroenteritis is a very common illness in neonates and infants and it is one of the important causes of morbidity and mortality in third world countries. Most of the complications are due to excessive fluid loss and electrolyte imbalance adversely affecting kidney functions. Renal failure is one of the critical causes of morbidity in these children.

Aim: We in the present study tried to evaluate the renal functions in infants with acute gastroenteritis reporting to our tertiary care teaching Hospital.

Methods: This cross-sectional prospective study was performed on $n=100$ infants with gastroenteritis admitted into the Emergency service room of Prathima Institute of Medical Sciences and Hospital, Naganoor, Karimnagar. The degree Dehydration was assessed both clinically and hematologically. Blood samples for estimation of leucocyte count, Urea, Creatinine, and electrolyte estimation were drawn initially on admission and subsequently, blood culture, urine culture, and radiologic procedures were undertaken whenever indicated.

Result: There are 16 cases with Blood urea more than $84 \mathrm{mg}$, indicating $16 \%$ of renal failure in the total number of cases studied, taking blood urea more than $20 \mathrm{mg}$ as the criterion. But considering urinary output there are 18 cases with urinary output less than $300 \mathrm{ml} / 1.73 \mathrm{M} 2$ /24-hours. All these cases show creatinine values of more than $1.5 \mathrm{mg} \%$. The glomerular filtration rate is decreasing as the severity of dehydration is increasing and fractional excretion of Sodium is diminishing with an increase in the severity of dehydration.

Conclusion: The biochemical parameters like serum creatinine, blood urea, the urinary volume must be routinely in all cases of dehydration along with urinary indices like FeNa and R.F.I to detect the early onset of acute tubular necrosis. Prompt administration of intravenous fluids in acute gastroenteritis will go a long way in minimizing the mortality and morbidity among the infants.

Keywords: Renal Functions in Infants, Acute Gastroenteritis, dehydration

\section{Introduction}

Gastroenteritis (Acute diarrheal disease) in infancy constitutes one of the common problems in children under-5 in most developing countries in the world. The situation concerning the Infantile gastroenteritis in these regions is at present depressing because of the excessive incidence of diarrhea in infants, their lack of resistance to fight the causative pathogens, the greater ability of children to develop water and electrolyte disturbances, and the widespread problem of malnutrition and undernutrition. Gastroenteritis is the second commonest cause of infant mortality in most tropical countries. The overall incidence of acute gastroenteritis ranges from 1.3 to 2.3 episodes of diarrhea per year in children aged less than five years. It is estimated that more than 300 US children die from this illness ${ }^{[1]}$. In developing nations like India diarrhea is the major killer and cause of illness approximately diarrhea causes around 3 million childhood deaths in the developing world ${ }^{[2]}$. Mortality and morbidity in infantile gastroenteritis are closely related to the state of dehydration and electrolyte balance, of which there is a much finer adjustment in infants as compared to the adult. Acute volume depletion due to fluid loss in gastroenteritis may reduce the renal blood flow and cause renal cortical necrosis ${ }^{[3]}$. This results in varying degrees of pathological changes in kidneys ranging from a large area of cortical destruction to minor necrotic lesions ${ }^{[3]}$. Therefore, urgent replacement is indicated to prevent irreversible kidney damage. The onset of acute tubular necrosis can be detected early by estimating creatinine clearance, Fractional excretion of sodium, serum creatinine and blood urea [below 1]. It is, therefore to send the blood for serum electrolytes estimation, maintain input and output charts and to replace the fluids and electrolytes promptly in acute diarrheal disease.

\section{Material and Methods}

This cross-sectional prospective study was performed on $n=100$ infants with gastroenteritis admitted into the Emergency service room of Prathima Institute Of Medical Sciences and Hospital, Naganoor, Karimnagar of the $n=100$ infants studied $n=38$ were between 3-6 months of age, $n=30$ were between 79 months and $n=32$ between 10 months to one year of age. Inclusion criteria: All the infants with diarrhea, vomiting due 
to gastroenteritis reporting to our Hospital. Exclusion criteria: Diarrhea and vomiting due to other causes, infants with congenital abnormalities, intestinal obstructions and renal dysfunctions due to other causes. Those cases which showed a discrepancy between clinical and hematological values regarding the degree of dehydration were excluded from the present study. All the babies with protein calories malnutrition were excluded from the study.

The degree Dehydration was assessed both clinically and hematologically. Table 1 gives a scoring system to assess the severity of dehydration clinically. Severe cases may score over 8; moderate cases ( $5 \%$ dehydration) would get a score of $4-8$ and mild cases less than 4. A score of 2 for anyone of the categories mentioned above actually indicates a severe type.
Hematologically the degree of dehydration was confirmed by estimating the Hematocrit by using the Micro method wherein, Blood obtained by heel puncture was taken into a capillary tube, which was then sealed at either end. It was then placed in the Adam's Hematocrit Chamber and is subjected to centrifugation (in the Adams READACRIT) at the speed of 5000 revolutions per minute for 5 minutes, following which the hematocrit was directly read from the scale that is attached to the chamber. Normal P.C.V. infants range between $33-35 \%$. The Body water constitutes $70 \%$ of the Bodyweight in infants of which ECF constitutes $30-35 \%$. Dehydration is graded depending on the P.C.V. values, 35\% - 40\% as Mild dehydration, $41 \%$ - $45 \%$ as Moderate dehydration, $46 \%$ and above as severe dehydration. The basis for using the P.C.V. in grading dehydration as follows:

\section{ASSESSMENT OF DEHYDRATION ${ }^{[5]}$}

\begin{tabular}{|c|l|c|c|c|}
\hline \multicolumn{2}{|c|}{ Signs } & Score 0 & Score 1 & Score 2 \\
\hline 1 & Appearance & Normal & Fretful and / Restless & Semi coma \\
\hline 2 & Eyes & Normal & Lusterless & $\begin{array}{c}\text { Sunken eyes with the cloudy } \\
\text { cornea and staring }\end{array}$ \\
\hline 3 & Ant. Fontanelle & $\begin{array}{c}\text { Normal or slightly } \\
\text { sunken }\end{array}$ & $\begin{array}{c}\text { Moderately sunken or } \\
\text { demonstrably depressed }\end{array}$ & $\begin{array}{c}\text { Well depressed cranial sutures } \\
\text { standing our }\end{array}$ \\
\hline 4 & Skin turgor & Normal & Moderate loss & Severe loss \\
\hline 5 & Tongue and mouth & Moist & Moist & $\begin{array}{c}\text { Very dry and coated lips } \\
\text { cyanosed }\end{array}$ \\
\hline 6 & Pulse and heart rate & Normal 13-140/min & Normal or rapid 160-180/min & Rapid and thready 180 \\
\hline 7 & Extremities & Warm & Warm & Cold and clammy \\
\hline 8 & Urine output & Normal & Oliguria & No urine for 12-24 hours \\
\hline 9 & Muscle tone & Normal & Normal and increased & Flaccid \\
\hline 10 & Thirst & Thirsty & Extreme thirst & $\begin{array}{c}\text { Not apparent because of the } \\
\text { poor general condition }\end{array}$ \\
\hline 11 & RESPIRATION & Normal & Mild & Deep sighing \\
\hline & a) Acidosis & b) Alkalosis & Slow and Shallow & Very slow and shallow \\
\hline 12 & Weight reduction & -10 $\%$ & 10 & \\
\hline
\end{tabular}

The bodyweight of the babies was measured by the weighing machine and crown-heel length by the stadiometer. The body surface area was then calculated using a nomogram. Bothe male $n=66$ and female $n=34$ infants were included in the study. Blood samples were estimated for leucocyte count, Urea, Creatinine, and electrolyte estimation were drawn initially on admission and subsequently, blood culture, urine culture, and radiologic procedures were undertaken whenever indicated. Intravenous fluids administered depending upon the type and severity of dehydration. For making up the deficit of fluids, $0.45 \%$ saline in $2.5 \%$ Dextrose and for maintenance $0.18 \%$ saline in $5 \%$ Dextrose was administered Sodium bicarbonate 
was given in cases of acidosis by using formula after estimating the $\mathrm{pH}$ and base-deficit by using the following formula:

$$
0.6 \text { X Body weight in } \mathrm{kg} X \text { Base deficit. }
$$

Potassium supplements were given at the rate of $2 \mathrm{mg} / \mathrm{kg} / \mathrm{day}$ after urine flow was established. Urine was collected utilizing condom drainage in the case of male infants and by using sterile urine collecting bags (CUTIFIXLNE, GARCON, AVEC. RACCORD, DE VIADANGE, ART NO.9403, 711, Made in France) in female infants.

The tips of the condoms were cut and attached to a sterile polythene tube using thread and adhesive plaster. The other end of the condom was brought out through a hole, circular in shape, made in a square piece of adhesive plaster of size 4 "x4". The circular opening was large enough to enclose the penis and scrotum at the root of the penis.

This piece was stuck to the perineum after the application of tincture Benzoin, carefully excluding the anal opening; the other end of the polyethylene tube was inserted into the collecting bottle (one pint) which was calibrated for urine volume. In the case of female infants, the circular opening of the sterile collecting bag was trimmed to an oval shape to negotiate the vulval opening. The skin in the diaper area was

\begin{tabular}{|l|c|c|c|c|c|c|}
\hline \multirow{2}{*}{$\begin{array}{c}\text { Age in } \\
\text { months }\end{array}$} & $\begin{array}{c}\text { Number of } \\
\text { cases }\end{array}$ & \multicolumn{2}{|c|}{ Sex } & \multicolumn{3}{c|}{ Severity of Dehydration } \\
\cline { 3 - 7 } & Male & Female & $\begin{array}{c}\text { Mild } \\
\text { PCV 35-40 }\end{array}$ & $\begin{array}{c}\text { Moderate } \\
\text { PCV 41-45 }\end{array}$ & $\begin{array}{c}\text { Severe } \\
\text { PCV > 45 }\end{array}$ \\
\hline $3-6$ & 38 & 14 & 24 & 12 & 17 & 9 \\
\hline $7-9$ & 30 & 26 & 4 & 7 & 23 & 5 \\
\hline $10-12$ & 32 & 26 & 6 & 6 & 58 & 3 \\
\hline TOTAL & 100 & 66 & 34 & 25 & & 17 \\
\hline
\end{tabular}

The range of values of serum Sodium and Potassium among the total number of cases studied. This shows that $n=74$ cases were Isonatremic, $n=16$ cases were hyponatremic and $n=10$ cases were hypernatremic as far as the Sodium levels were concerned. There were five $n=5$ cases of hyperkalemia and cleaned with spirit and after making sure that the area was dry, the bag was applied on to the perineum around the urethral opening. Care was taken to ensure that the adhesive surface was pressed firmly on to the skin posteriorly to prevent leakage and contamination of the specimen. The collection was started after the last voiding of the urine around 8 to 9 a.m. To ensure that the last aliquot of urine was also collected manual compression of the bladder was done. In no case, urinary catheterization or suprapubic puncture was done. Blood samples were again collected just before the removal of the urine collecting devices. About $5 \mathrm{ml}$ of blood was collected from the femoral vein after adequate sterilization of the part. Samples were immediately transported to the Biochemistry laboratory for estimation of creatinine clearance, serum electrolytes, calculation of renal failure index. The available data were recorded in the MS Excel spreadsheet and analyzed

\section{Results}

The distribution of total cases studied according to the age, sex and severity of dehydration maximum number of cases occurred in the age of around 3-6 months. The male to female ratio is about 2:1 showing the preponderance in males. The maximum number of cases was moderately dehydrated.

Table 2: Distribution of Age, Sex and Severity of Dehydration

$\mathrm{n}=3$ cases of hypokalemia. Isotonic dehydration is the commonest, hypotonic and hypertonic dehydration coming next to isotonic dehydration.

Graph 1: Range of values of sodium by SPSS version 17 on windows format.

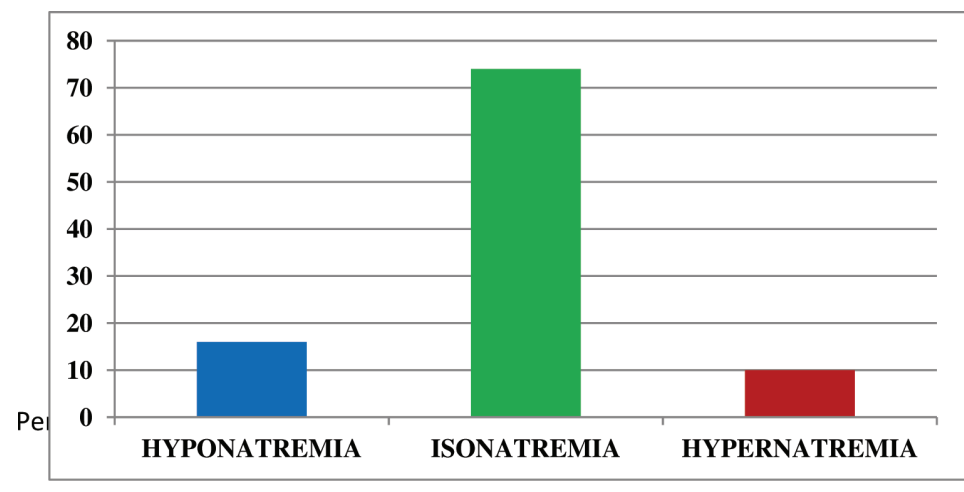


Table 3 shows, Range of values of blood urea and serum creatinine. There are 16 cases with Blood urea more than 84 $\mathrm{mg}$, indicating $16 \%$ of renal failure in the total number of cases studied, taking blood urea more than $20 \mathrm{mg}$ as the criterion.
But considering urinary output there are 18 cases with urinary output less than $300 \mathrm{ml} / 1.73 \mathrm{M} 2$ /24-hours. All these cases show creatinine values of more than $1.5 \mathrm{mg} \%$.

Table 3 : Values of Blood Urea and Creatinine

\begin{tabular}{|c|c|c|c|c|c|c|}
\hline \multicolumn{2}{|c|}{ Blood Urea in mg\% } & \multicolumn{3}{c|}{ Serum creatinine in mg\% } & \multicolumn{2}{c|}{$\begin{array}{c}\text { Urine output in } \\
\mathrm{ml} / \mathbf{7 3} \mathrm{M2} / 24 \text {-hours }\end{array}$} \\
\hline $\mathbf{1 0}-\mathbf{2 0} \mathrm{mg}$ & $>\mathbf{2 0} \mathrm{mg}$ & 1.0 & 1.0 to 1.5 & $>1.5$ & less than $\mathbf{3 0 0}$ & More than $\mathbf{3 0 0}$ \\
\hline 84 & 16 & 6 & 76 & 18 & 18 & 82 \\
\hline
\end{tabular}

Table 4 shows the mean values with standard Deviation of Blood urea, serum creatinine and urinary output concerning different degrees of dehydration. Blood Urea and Serum creatinine levels are showing a tendency to increase as the

severity of dehydration is increasing, whereas the output of Urine is decreasing as the severity of dehydration is increasing.

Table 4: Mean Values of Blood Urea, Serum Creatinine, and Urine Output

\begin{tabular}{|c|c|c|}
\hline Parameter & Degree of dehydration & Mean values \pm SD \\
\hline \multirow{3}{*}{ Blood urea (mg/dl) } & Severe dehydration & $100 \pm 12$ \\
\hline & Moderate dehydration & $68 \pm 8$ \\
\hline & Mild dehydration & $20 \pm 4$ \\
\hline \multirow{3}{*}{ Creatinine (mg/dl) } & Severe dehydration & $1.5 \pm 0.5$ \\
\hline & Moderate dehydration & $0.95 \pm 0.15$ \\
\hline & Mild dehydration & $0.4 \pm 0.2$ \\
\hline \multirow{3}{*}{$\begin{array}{l}\text { Urine output } \\
\text { (ml/1.73 M2 /24-hours) }\end{array}$} & Severe dehydration & $272 \pm 18$ \\
\hline & Moderate dehydration & $386 \pm 22$ \\
\hline & Mild dehydration & $467 \pm 15$ \\
\hline
\end{tabular}

The relation of Glomerular Filtration Rate, Fractional excretion of Sodium and Renal Failure Index to the degree of dehydration is shown in table 5 . The glomerular filtration rate is decreasing as the severity of dehydration is increasing and fractional excretion of Sodium is diminishing with an increase in the severity of dehydration. The renal failure index is also increasing as the severity of dehydration is increasing.

Table 5: Mean Values of Creatinine Clearance, FENa, and R.F.I.

\begin{tabular}{|l|c|c|}
\hline Parameter & Degree of dehydration & Mean values \pm SD \\
\hline \multirow{3}{*}{$\begin{array}{l}\text { CREATININE CLEARANCE ( G.F.R) } \\
\text { (ml/min/1.73 M2) }\end{array}$} & Severe dehydration & $22.37 \pm 6.66$ \\
\cline { 2 - 3 } & Moderate dehydration & $44.23 \pm 5.37$ \\
\cline { 2 - 3 } & Mild dehydration & $59.82 \pm 11.24$ \\
\hline \multirow{3}{*}{$\begin{array}{l}\text { FRACTIONAL EXCRETION OF } \\
\text { SODIUM (FeNa) }\end{array}$} & Severe dehydration & $0.36 \pm 0.13$ \\
\cline { 2 - 3 } & Moderate dehydration & $0.44 \pm 0.15$ \\
\cline { 2 - 3 } & Mild dehydration & $0.76 \pm 0.13$ \\
\hline \multirow{2}{*}{ RENAL FAILURE INDEX [RFI] } & Severe dehydration & $0.67 \pm 0.39$ \\
\cline { 2 - 3 } & Moderate dehydration & $0.56 \pm 0.02$ \\
\cline { 2 - 3 } & Mild dehydration & $0.45 \pm 0.5$ \\
\hline
\end{tabular}


Total $n=5$ cases died out of $n=100$ cases studied representing $5 \%$ of the cases studied. Out of those $n=5$ cases, $n=3$ deaths were in the age range of 3-6 months. In the age group of 3-6 months, out of a total of $n=38$ children admitted $n=3$ died. $\mathrm{N}=3$ cases died due to renal failure representing $3 \%$ of the total sample studied $n=1$ case died with severe Bronchopneumonia and 1 case died to severe septicemia.

\section{Discussion:}

In the current study, we found the maximum number of cases of acute gastroenteritis occurred in younger children aged 3 6 months and females were more affected as compared to males. There could be two reasons for this one is 5-6 months is the age when the child starts to take other foods apart from the exclusive breastfeeding which may lead to GE and second is females are more affected and there is a common notion in this country and the male child is often cared more compared to the female child. According to the causes of neonatal mortality in India published in 2011 showed that diarrheal diseases caused deaths of 0.3 Million. They also found that girls in south India have four times higher mortality from diarrheal diseases ${ }^{[6]}$. In this study, we found isonatremia was the commonest type of dehydration. It was found in $74 \%$ of the total cases studied. Hyponatremic dehydration was noted in $16 \%$ of cases in our study.

Taking blood urea into consideration, there were $n=16$ cases of renal failure, which showed blood urea more than $100 \mathrm{mg} /$ dl. Taking urine output of $<300 \mathrm{ml} / 1.73 \mathrm{~m} 2 / 24 \mathrm{hrs}$ as the criterion for renal failure, there were $n=18$ cases. All the cases who were diagnosed as a renal failure based on urine output, showed plasma creatinine levels of $>1.5 \mathrm{mg} \%$. Plasma creatinine $<1.5 \%$ may be a better guide for diagnosing renal failure as it correlated well with urinary output in contrast to blood urea levels which correlated poorly with urinary output. Ismail HK et al; in their study found the $5.12 \%$ of cases of renal failure were due to gastroenteritis in children ${ }^{[7]}$. Ali Duzova et al; ${ }^{[8]}$ found the cause of kidney failure in children due to gastrointestinal disorder in the newborn was $1.9 \%$ and in $>1$ month it was $4.1 \%$ and the total was $3.4 \%$. In this study, we found a total of in our study 18 cases $(18 \%)$ developed renal failure. It could be because of the smaller sample size in this study and our hospital is a tertiary care hospital only complicated cases might have been referred from lower levels leading to an increase in the number of renal failure cases.

Biochemical markers are important for the diagnosis of kidney injury and also adopting an optimum strategy for better clinical outcomes. The collection of urine and analysis is relatively discomforting therefore serum analysis of renal function markers like creatinine, urea, uric acid, electrolytes, and BUN are estimated ${ }^{[9]}$. Urea and creatinine are good indicators of $a$ normal functioning kidney and an increase in the serum are indications of kidney dysfunction ${ }^{[10]}$. BUN and serum creatinine are widely accepted and most common parameters to assess renal functions ${ }^{[10,11]}$. In our study, the levels of blood urea and creatinine were found to be increasing with increased severity of dehydration and inversely with urine output. Blood urea nitrogen (BUN) level is another indicator of kidney function. Urea is also a metabolic byproduct that can build up if kidney function is impaired. The BUN-to-creatinine ratio generally provides more precise information about kidney function and its possible underlying cause compared with creatinine level alone. BUN also increases with dehydration. Infants have normal levels of about 0.2 or more, depending on their muscle development. FeNa is the fractional excretion of sodium the interpretation of FeNa is based on the fact that intact tubules reabsorb sodium in pre-renal states while injured tubules do not $^{[12,13]}$. Studies have shown that FeNa is a tool to differentiate the functional and structural acute kidney injury. In this study we found FeNa to be reduced based on the severity of dehydration. The values of the Renal failure index were also increased in cases of severe dehydration. Total $n=5$ cases died out of 100 cases studied representing $5 \%$ of the total. S.K. Behra et al; and Srivastava. $\mathrm{M}$ et al; reported $9.5 \%, 14.7 \%$ of mortality in their series of cases ${ }^{[14,15]}$. The lower incidence of mortality in our study could be because of the fact, in the present study, P.E.M cases that are prone to infections are excluded and better diagnosis and prompt treatment done in our cases.

\section{Conclusion}

The biochemical parameters like serum creatinine, blood urea, the urinary volume must be routinely in all cases of dehydration along with urinary indices like FeNa and R.F.I to detect the early onset of acute tubular necrosis. Prompt administration of intravenous fluids in acute gastroenteritis will go a long way in minimizing the mortality and morbidity among the infants.

\section{REFERENCES}

1. Jaffar, S., Leach, A., Greenwood, A.M. et al. Changes in the pattern of infant and childhood mortality in upper river division. The Gambia, from 1989 to 1993. Trop. Med. Int. Health 1997; 2: 28-37.

2. Mahendrakar, A.G., Dutta, P.K. and Urmil, A.C. et al. Study of the medico-social profile of under-five children suffering from diarrhea disease. Indian J. Mat. Child Health1991; 2: 127-130.

3. Kleigman. Deficit therapy. In: Kliegman, Stanton, Schor, Game, Behrman (Eds.) Nelson Text Book of Pediatrics. 19th ed. Philadelphia: Saunders; 2012;247-248

4. Konstantinos Makris, Loukia Spanou. Acute Kidney Injury: Diagnostic Approaches and Controversies. Clin Biochem Rev 2016;37(4):153-75.

5. Robert M. Kliegman \& Bonita M.D. Stanton, Joseph St. Geme, Nina F Schor. Nelson textbook of Pediatrics 19th ed. Philadelphia: Saunders; 2012;1333. 
6. Dr. Diego G Bassani, Prof Prabhat Jha, Causes of neonatal and child mortality in India: nationally representative mortality survey. Lancet 2010; 376(9755):1853-60.

7. Ismail Hassan K, Hodan M J, Li C. A Retrospective Study of Acute Renal Failure in Children: Its Incidence, Etiology, Complications, and Prognosis. Cureus 2017; 9(5): e1274.

8. Ali Duzova, Aysin Bakkaloglu, Mukaddes Kalyoncu, Hakan Poyrazoglu et al. Etiology and outcome of acute kidney injury in children. Pediatr Nephrol 2010; 25:1453-61.

9. Gowda S, Desai PB, Kulkarni SS, Hull VV, Math AAK, Vernekar SN. Markers of renal function tests. N Am J Med Sci. 2010;2(4):170-73.

10. Kamal A. Estimation of blood urea (BUN) and serum creatinine level in patients of renal disorder. IJFALS. 2014;4(4):199-02.

11. Suresh G, Ravi Kiran A, Samata Y, Naik P, Kumar V. Analysis of blood and salivary urea levels in patients undergoing hemodialysis and kidney transplant. J Clin Diagn Res. 2014;8(7): ZC18-20.

12. Espinel $\mathrm{C} . \mathrm{H}$. The FeNa test use in the differential diagnosis of acute renal failure. Journal of the American Medical Association. 1976;236(6):579-81.

13. Perazella M. A., G. Coca S. Traditional urinary biomarkers in the assessment of hospital-acquired AKI. Clinical Journal of the American Society of Nephrology. 2012;7(1):16774.

14. Behra S.K. Incidence and mortality of hospitalized diarrhea cases. Indian journal of pediatrics 2001; 52:34.

15. Srivastava A.K. A clinical and etiological study of diarrhea in hospitalized children in Lucknow. Indian pediatrics 2002; 36: 122.

How to cite this article : Sandeep S. Assessment of Renal Functions in Infants with Acute Gastroenteritis and Dehydration. Perspectives in Medical Research 2020; 8 (2):94-99. DOI : 10.47799/pimr.0802.20

Sources of Support: Nil, Conflict of interest: None declared 